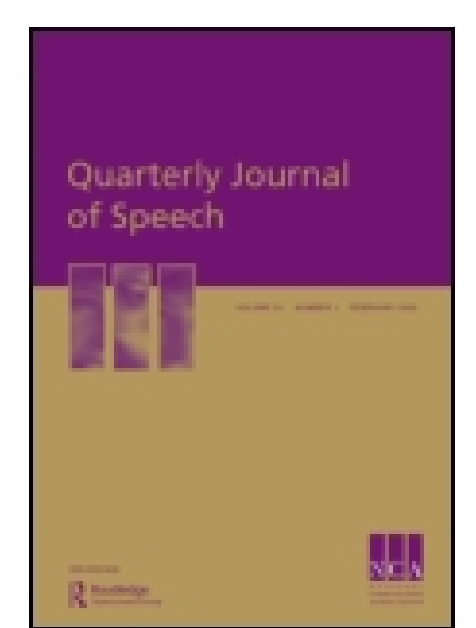

Quarterly J ournal of Speech

Publication details, including instructions for authors and subscription information:

http:// www. tandfonline.com/loi/ rajs20

\title{
Persuasion: Principles and method
}

\section{Charles H. Woolbert ${ }^{\text {a }}$}

University of Illinois

Published online: 05 | un 2009.

To cite this article: Charles H. Woolbert (1919) Persuasion: Principles and method, Quarterly J ournal of Speech, 5:3, 212-238, DOI: 10.1080/00335631909360742

To link to this article: http:// dx. doi.org/ 10.1080/00335631909360742

\section{PLEASE SCROLL DOWN FOR ARTICLE}

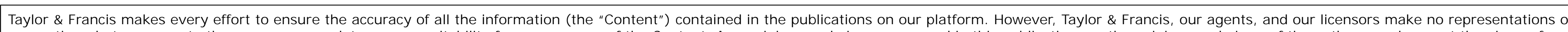

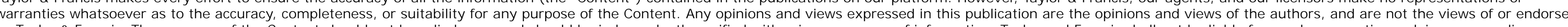

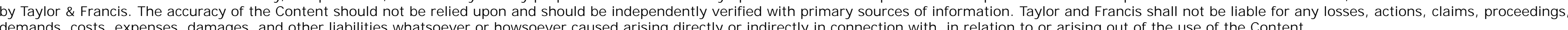
demands, costs, expenses, damages, and other liabilities whatsoever or howsoever caused arising directly or indirectly in connection with, in relation to or arising out of the use of the Content.

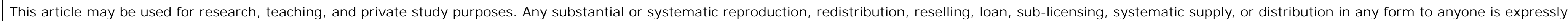
forbidden. Terms \& Conditions of access and use can be found at http://www.tandfonline.com/page/terms-and-conditions 


\section{PERSUASION: PRINCIPLES AND METHOD ${ }^{1}$ \\ PART III. Synthesis \\ CHARLES H. WOOLBERT \\ University of Illinois}

TN THE two earlier papers in this series the following points were made: All speech and writing is intended to secure action; the type of action common to all verbal address is incorporated in the idea of Acceptance; every act of Acceptance implies the presence of propositions which can be stated in words and which can be shown to be logically coherent; the inducing of Acceptance is a matter of finding and using such propositions as, when accepted as true, lead to the granting by the hearers of the speaker's wish, or purpose; thus in all communication or persuasion there are three factors to be reckoned on, the speaker, the hearer, and the propositions presented for acceptance; the standard whereby propositions shall be chosen to win results must be that of Sufficiency, surely not that of absolute finality.

Turning these principles then into specific steps, for purposes of method, we find the following stages in Analysis necessary:

STEP 1. Choose definitely the action desired.

STEP 2. Convert this into a demand made upon the given audience for the action desired, thus connecting speaker's purpose and audience's acting nature. This properly takes the form of an imperative sentence.

STEP 3. Convert this demand, imperatively stated, into a proposition, stated declaratively, which will incorporate action desired, demand for it, and the audience's relation to the demand. This takes the form commonly known as the Proposition, or resolution, for discussion. Being in propositional form, it is the groundwork of logical processes that necessarily arise upon it. In this way full connection is made between the psychological factors of wish of speaker and acting nature of audience, and the logical factors implied in the framing of a proposition.

STEP 4. Analyse the hearers' acting natures, as individuals; ascertain the balance of the biological needs and tendencies of

IThe third of a series of papers appearing in the QUARTERII JOURNAL OF SPEECH EDUCATION on this general subject. For the previous parts see the two preceding numbers of this publication. 
the audience as persons. Determine what they will and will not consent to do.

STEP 5. Analyse the hearers as members of social groups; determine what they can be led to do as a group and what in the presence of others they will refuse to do.

STEP 6. When dealing with congregated audiences, study them for peculiarities involved in the situation, to ascertain their temper as an audience.

STEP 7. Gather the propositions deemed relevant to the task, and analyse them to ascertain their logical relationship one to another-the task of brief-making, to ascertain the logical strength of conclusions and inferences.

These steps, when followed out judiciously, answer the questions: How does a speaker know what to talk about? What is the basis for his actual use of words before his audience? How does he arrive at a central topic, or theme? Whence is a proposition derived? How is the bridge made between the psychological interests involved in action and demand for it on the one hand, and the use of propositions that are to induce the action, on the other? This method accords with the obvious fact that propositions, or resolutions, for discussion do not drop out of a clear sky; they come from a wish plus an insistence that others accede to that wish, plus the presentation of a proposition offered as a valid reason why those others should grant that wish. Thus a properly worded Main Proposition, as we would do well to call it, or resolution, must make provision for (1) the speaker's wish for action, (2) the aspect of the audience's acting nature that is to be touched off, and (3) a truth as represented in the predication of the proposition. No discourse is possible that has not behind it just such a Main Proposition, or Resolution, derived always from these three factors or wish, action tendencies, and a truth.

These steps represent the open joints in composition; they are the places where trouble starts and where inspection reveals. what the trouble is and what can be done about it. They are of such a nature that in any one of them mistakes can be made that will wreck the whole enterprise of getting a desired specific result. Yet there holds at no point an absolute standard, the only one possible being that of sufficiency; always gauged by the knowledge and sagacity of the man who tries to win others to do his will. 
The Main Proposition

It is in the framing and phrasing of the Main Proposition that all the theory previously offered in these papers takes head. Every desire for a result, when brought before a given audience, points to one proposition, in the presence of the existing known facts, which better than all others states the whole case in a sentence for the speaker. The search must not be for $a$ proposition, but for the proposition. When properly selected and stated, it amounts to a resolution to be presented and accepted by the hearers; and when devised properly to fit the spealker's wish, audience's acting nature, and the known facts, its acceptance by the audience is the action sought.

This is not difficult of explication. Suppose we are taking subscriptions for a new $\mathbb{Y}$. M. C. A. building; we are addressing an audience largely made up of parents and adherents of family life; we know that they react to an appeal on the basis of morality and welfare. The speech we make to them could easilly grow out of this Main Proposition, "The $\mathbb{Y}$. M. C. A. building merits public support." But this is too cosmic; there is nothing is this, even though accepted fully, to urge any given man to subscribe; he $\mathrm{knows}$ he is not the general public, a disembodied moral force, and most of us refuse to assume responsibility for abstractions; under such circumstances we gladly wait for the neighbors to move first. An appeal that followed the above proposition rigidly, would get few dollars. But a more specific recognition of the precise acting nature of the given audience suggests a proposition much more efficacious, "The moral well-being of the boys of this city makes it obligatory upon every person present to subscribe all he can to this building."

Again we might be asking for votes against the saloon. We could start from this as Main Proposition: "The saloon should be abolished"; but that again would be cosmic, and everybody present could accept it and still do nothing to hurt the saloon. Hardly so, however, if the speaker speaks from this as Main Proposition, "Every voter present should go forth from here determined to do all he can to put the saloon in this town out of business."

The vital point is this: the acceptance, sufficiently strong, of either of these more specific propositions, is the action desired; in either case it is just what is wanted under the circumstances, 
the maximum of what the occasion allows, and no other action is more worth seeking. If the $\mathbf{Y}$. M. C. A. audience accept that proposition, they will give up the money and do the speaker's wish; if the other audience develop a strong determination to go out and hit the saloon business-especially if the speaker shows them how they can do it - then his wish is fulfilled; in either case the desired action is accomplished. And that is the beginning and the end of all communication, public address, and written treatise. The Main Proposition can always be so worded that the acceptance of it is, or necessarily assures, the action desired.

The relation of this subject to intercollegiate debating calls for a special statement. If we were to take as typical the kind of Main Propositions used in contest debating, we should meet ordinary, work-a-day audiences neither very directly nor very effectively. A college debate proposition is a very narrow type of its kind; it is aimed at three gentlemen imagined as possessing cosmic minds barren of bias and cleansed of all personal tastes, ambitions, desires, or predilections. Very correct and proper for the game of intercollegiate debating; but this standard, when applied to audiences as society provides them, merely bores people and leaves them wondering what it is all about or why the speaker didn't put it into a pamphlet and send it around. It gets few votes, subscriptions, sales, or converts. An audience always has a peculiar character blend, a specific group flavor; and the speaker who has the knowledge of facts and the sagacity to use them aright, who can state his Main Proposition specifically to hit off this group note, can drive all the time at a vulnerable point straight and hard. Otherwise he will indulge only in various degrees of scattering.

Clearly under this conception of the manner of making up a Main Proposition, there can be no such concept as a division into "purely logical" considerations and others purely "emotional." The ideas incorporated in these two terms are most obviously provided for when the Main Proposition is got at in the manner just described. It is a fair case of unity of process.

STEP 8-Select as Main-Headings propositions that touch off the hearer's acting nature.

But, it may be asked, are we to treat the Brief as if it too were not solely rationalistic? as if it were to be bound up with bias, prejudice, and the emotions? The theory now being presented has 
no other answer than Yes; the Brief is, like every other step in the process, a matter both of the intellectual processes and the emotional, as these two terms are commonly accepted. It is not enough that some logical comnection be found and shown; this connection must be also adequate, acceptable, impressive. $\mathbb{A}$ brief could say:

A. The Government should retain the railroads; for

1. There are so many of them and the government is so large.

2. Government officials can consider the whole question at one view.

3. The Government will enjoy running them.

These reasons all flow logically from the proposition they are supposed to render acceptable; yet they are clearly not adequate to support it sufficiently, even though accepted as true. Relevancy, in other words, admits of degrees of impressiveness, of power to grip, of adhesiveness as well as cohesiveness. If there is meaning to a difference between the intellectual and the emotional at this juncture, it must be in this, and it is a difference in depth and penetration into inner and hidden mental processes.

A more impelling set of reasons would be:

A. The Grovernment should retain the railroads; for

1. Private ownership has been an obvious failure.

2. Government control has been successful.

3. Government control is free from the evils necessary to private ownership and control.

Here are reasons, which, if accepted each in its turn, would make the subordinate propositions sufficiently acceptable.

Let it be enough here to point out that logical relevancy in the making of a brief is not the sole desideratum; impressiveness of connection is also vital. These main headings follow the same rule as the Main Proposition; they must pull at a live tendency to have any effect whatever. Herein lies the difference between brief-headings that grip and those that fumble. Men have no action grooves toward making governments happy, but they have wide-open channels for insisting upon efficiency in management. When headings, or main reasons, serve the two purposes of answering the question Why? or How do you know? and at the same time search out active tendencies, they provide adequately 
for both the "intellectual" and the "emotional," and the two ends are served by one process; not by two.

THE OUTLINE

STEP 9-Make an outline in the form of a coherent paragsaph.

That the brief is not an ideal outline for a composition has for some time been recognized. Such it may be for speeches of a restricted type; but it may serve every purpose for which it is properly intended and still lack the proper characteristics for an effective outline. What it lacks by way of necessary traits for outline purposes, are the two elements of Order and Proportion. Occasions are conceivable when the order of presenting material is insignificant, providing logical relevancy is maintained; or perchance providing the brief happens to hit the best order. Also proportion may be of little concern or else provided for by the brief. Yet in all justice to the needs of briefing a brief can be made in any order of main-headings, and the proportions of it will almost always be more ample than the speech that comes from it; for in sincere and thorough work the brief ought to be full sized, as large as practicable, no matter what the length of the speech. In fact a short speech frequently demands a fuller brief than a long one; as President Wilson says: To prepare for a five-minute speech, takes three hours; for a half-hour's speech two hours; while for a two hours' speech one needs no preparation at all! The brief is not necessarily a satisfactory outline.

The best form of outline is a complete paragraph. Another distinction to be made between the brief and the outline is that the brief is distinctly a matter of analysis, of focussing upon the pieces to observe the relation of the several parts; while the outline is a matter of composition, a putting together to get a compound effect. In so far as a brief compounds, it is outline; otherwise it is analysis, criticism pure and simple. But the outline proper has no other function than to produce a compound with a purely constructive, non-critical, function. It makes definite movement toward getting for the Main Proposition all the acceptability from the hearer that it can. It is actually to the hearer presented; the brief is not. So the outline must be a constructive aggregation of propositions defending the validity of the Main Proposition; from which the whole speech must be derived.

From the brief what propositions shall be chosen for the outline? The answer grows from the analysis of the audience's 
special tendencies: those propositions which, when knit logether into logical discourse render the Main $\mathbb{P}$ roposition thoroughly acceptable to the audience, if accepted as true. In other words, the outline should be a telescoped composition made up of especially significant propositions, knit together with such close logic as to cause the certain acceptance of the Main Proposition. Significance of propositions is a matter of pulling power upon a live tendency. So the outline then must be a composition of propositions that singly encounter an open action path and collectively give logical validity and action-inspiring vigor to the Main Proposition. In saying this we have described a proper paragraph.

But there is nothing in this to demand that the significant propositions be from the start acceptable to the audience as bare propositions. It will be hard sledding if all are unacceptable. While some may well be chosen for their sure acceptability, others may be held as of doubtful validity; and still others may be even bitterly opposed. Apart from their individual acceptability they serve their turn if they knit together well into a logical compound and if the collective pull of the whole is deemed overpowering for the audience in question. The stronger the pulling power throughout the outline, the better it supports the Main Proposition. An ideal outline, then, is a series of propositions, each of which, if made acceptable as truth, has power to move the audience to a strong reaction, and all of which taken collectively and united by strong logical links, commend the Main Proposition to the audience as inevitable and irresistible.

\section{ORDER}

STEP 10-Arrange topics in the outline by certainsy of drawing power.

In general, every speech should begin with "sure-fire" stuff; the opening "point" should be one the audience finds easy to take; in fact, one they rather like. This is why speeches so often begin with remarks complimentary to the audience, with pleasantries about "your beautiful city" or "this great occasion" or "this remarkably intelligent audience." But on a higher plane the opening can be with something universal, cosmic, like a moral principle, an ideal, a sentiment, an aesthetic attitude. In any case it may well be something accepted in common by the 
whole audience. With a start made by the use of such topics, progress can be made to topics less acceptable or to topics wholly opposed by the audience.

In the presence of formal audiences there is usually wisdom in an approach that penetrates from the outward toward the centre, beginning with the social crust and gradually working through it to the inner man beneath; starting with large social interests and closing in later on personal, unsocial attitudes. The most obvious social interest always is something connected with the immediate occasion; remarks about that at the start are almost always in order. From this conclusion the part of wisdom seems to be to take up at first topics dealing with national and state interests, if not interests of the universe; then on down to community, cult, coterie, or sect; thence into the inner desires of the individual man; bread-and-butter advantage, social and political power, protection from danger. For a closely homogeneous crowd which feels freedom from formality, the reverse order might be appropriate; the dominant personal interest could be touched off at the start, and the large social interests, if used at all, presented last. The really powerful thing always is to reach the man as. individual; in a socially suspicious group, approach only by way of accepted social attitudes; in a group socially without repressions and inhibitions, one may go straight to the appeal to personal advantage. A general mass meeting calls for a speech beginning with broad cosmic topics; a labor union meeting or a church council can take up a narrow class interest from the start.

STEP 11 -Give the outline its best logical consecutiveness.

This arrangement gives to the outline its best "emotional" order. The next need, though possibly the first in importance, is to give it logical coherency, logical consecutiveness. Little need be offered by way of explication of this need; it is universally demanded. Example will make the point better than any other method. Imagine a group keenly interested in helping the workingman, particularly the underpaid, exploited class. Suppose the speaker has decided that his Main Proposition for the occasion is, "The principle of the minimum wage will provide you with your solution of the problem of the underpaid worker." With that as the topic sentence we can now frame a paragraph that will be 
an outline for the speech that is to ensue. The paragraph outline could take the following form:

Dissatisfied labor is a menace to society. Labor must be protected. The state has an interest in labor's condition. Capital can afford to share more of its profits with the worker. Some means must be found to provide the underpaid worker with higher wages. The minimum wage principle has been a success where tried.

This looks fairly good; it is rather superior to the average of outlines, especially in that it possesses some shred of logical consecutiveness. But we can make the logical inevitableness much more apparent, by improving the logical connectives used:

Dissatisfied labor is a menace to society. To remove this menace from society, labor's dissatisfaction must be allayed. Such dissatisfaction can best be removed by society itself through the powers of the state. The state, then, must take such action as is needed. To accomplish this result some means must be found whereby the state can relieve the underpaid laborer. This means will be found best in the establishment of the minimun wage. It is just to employer, helpful to the worker, and feasible under state direction. That it will accomplish the result desired is demonstrated by experience in countries that have tried it.

Logical coherency shows itself in actual discourse by the validity of the connectives used. When conjunctions and connective phrases are used, they must appeal to the hearer-and the speaker too-as making sense; if the ands and buts and therefores make, not sense, but nonsense or untruth, then the logic is insufficient. But if they seem to speak truth and to carry the marks of good sense, then they serve the turn of logicality. So that when the speaker adds a close-knit logical coherency to the pulling power of propositions and to an order that advances guardedly upon inner and vital interests, he can give to his outline the maximum of effectiveness.

\section{PROPORTION}

STEP 12-Expand the outline to fut the needs of the occasion.

Different occasions call for outlines of different degrees of complexity. Sometimes two or three topics will do; at other times if the spirit of the outline and its general course are to be gripping and conclusive, it must be amplified into many and even more propositions. A four-minute speech and a three-day impeachment need working plans of decidedly different complexity and dimensions. Again, for this end, knowledge and sagacity must be requisitioned. The outline presented above can readily be amplified to twice, yes four times, its length, and still lack neither pulling power nor logical consecutiveness. It can be 
modified for speeches of almost any length, and without affecting its order, either emotional or logical.

Thus the outline that best serves the ends of Persuasion is a series of declarative sentences strongly influencing, when accepted as true, certain live action tendencies in the audience and connected consecutively by approved links of opening reasoning. Then when properly expanded it gives the skeletal frame of the actual speech, by presenting ready for use the topics for the paragraphs necessary to make up the discourse proper. It leaves the speaker ready to break out into coherent, significant discourse. With such an outline behind him when he begins to talk or write, he can talk sense, he can make the sense vital and interesting, and he can lead the audience in the direction he wishes them to go-straight toward acceptance of his Main Proposition, which is equivalent to yielding him the action he desires.

\section{Method of Topic Development}

STEP 13-Decide how each topic in the outline is received by the audience.

The speaker is now ready for logical, running discourse. Here for the first time he fires upon his audience; all previous moves have been by way of selecting, storing up, and arranging ammunition. At the point where outline turns to amplified paragraphs the crux of Persuasion looms up. When the speaker breaks into actual talk he faces his greatest danger. Here the very stuff of speech takes form; for when the topics are properly developed into paragraphs of fluent discourse, the thing is almost done. It is this developing of the outline topics that forms probably the most vital problem in the whole process. Certainly we shall see that it offers the largest possible scope for wide knowledge and keen sagacity.

In the development of topics into paragraphs, now, where shall we look for the basis of difference in method? Method there must be, and differences are most obviously inescapable. Where shall they be found? Here the same answer applies as at all other junctures in the process: in the occasion. The objective attitude must still be kept religiously; the method must not lose sight of the hearer or of what the hearer is asked to do-to accept propositions. The propositions to be accepted are the topics of the outline, which in turn are used to make acceptable the Main Proposition, which incorporates the action desired. The problem is 
to make them acceptable. No, it is more; it is to make them acceptable sufficiently. As they stand, they must of necessity represent entirely different degrees of acceptability to the audience. Be it remembered that they are chosen for their individual pulling power and for their joint logical consecutiveness and cumulativeness. So the question arises, How shall propositions differently accepted by auditors be developed into flowing paragraphs so that each paragraph and each topic will do its best for the Main Propositions? Answering this question; "How?" gives us the cue; it is clearly a matter of the manner of the treatment, of method.

If method is the secret, where are found the methodological differentia, the different ways of doing the thing? Answer: it is all a matter of differences in acceptance attitude. The inevitable differences in method grow from the different acceptance attitudes entertained by the hearers. Such differences in the set of the hearer plainly call for different treatment in the choice and handling of the facts to be presented, those facts that are to make suffciently acceptable the paragraph topic. So it is fair to say next that the number of these methods will conform to the number of acceptance attitudes possible for hearers. How many and what are these attitudes? In number, three; in kind, (1) acceptance outright, (2) hesitancy, doubt, ignorance, or indifference, and (3) rejection, suspicion, opposition, hostility.

For short let us call these three attitudes, (1) acceptance, (2) hesitancy, and (3) opposition. We should be saying precisely the same thing if we call these three different aspects of belief; (1) belief, (2) doubt, and (3) disbelief. Acceptance is used here as a means of keeping terminology consistent with what has gone before. For each of these three attitudes there is needed a method of treating the facts in a way distinct and unique from each of the others. The discovery of the nature of these three methods lies in analyzing the situation where acceptance is the end sought.

At this point a review is demanded.2 To deal adequately with the problem of acceptance, we must analyse acceptance to find out what it yields in differentia for purposes of outlining methods; to see how much is contributed to method in paragraph devel-

2 What follows is a summary of the article on "The Place of Logic in a System of Persuasion"; QUARTerLy JOURAal OT Sperecil EDUCATION: Jan. 1918; Vol. IV, No. 1, 19-39. 
opment by an analysis of the way acceptance ever takes place. The problem is logical, a matter of the "laws of thought," the application of law to the use of words in discourse.

Words are but one way of manipulating propositions. The same effect precisely is produced by making gestures, grimaces, and postures of all kinds, visible to an observer. But the very identical effect, except for the possibility of inspection by an observer, is produced by changes in blood pressure, action of glands, tensions of muscles that tighten and relax unnoticed and unnoticeable. This applies especially to the muscles of the face, throat, jaw, tongue, and larynx. ${ }^{3}$ The norm for a system of Persuasion is found in the use of words for speech; what we are trying to find out is how the act of acceptance and the use of words cohabit. We get the answer by taking cognizance of the fact that words are a medium of social intercourse; whatever else words are, they are social. So that to get at the inwardness of the acceptance of propositions for use in a theory of Persuasion, we are forced to look upon verbal responses, worded acceptances, as the basis for our differentia. Better yet, we are to look for differences in social exposure in the accepting of propositions.

Propositions are validated, accepted as true, that is conclusions are drawn, inferences made, facts approved, on three levels, three planes of social exposure. And on each level they employ different degrees of rigor in the adherence to logical law.

(A) Belief Made on the Level of Hidden Inference. Our purest subjective convictions are made out of sight of others. The experiences of life fill us with convictions, truths, which are entirely personal, subjective, individual; therefore biased, prejudiced, and for the most part in the nature of illusions. They are stored up in the mind as mental habits, habitual actions, and pet beliefs. In this type of reasoning-for a type of reasoning it is at bottom-logical rigor is not necessary; in fact it is most of the time an arrant nuisance and given short shrift; we believe, on this level, just what we want to believe, just what our animal natures dictate. In such kind of reasoning discrimination of likenesses and differences is obviously vague, shallow, casual; the abstraction of essentials is almost ridiculously careless; and generalization is most sketchy. All of which is by way of saying that

${ }^{3}$ See the first of this series of articles; QUARTERLy Jourisal OF SPEECH Educatron; Vol. V, No. 1; pp. 14-18. 
it is reasoning at its poorest. Hence our subjective beliefs and rationalizings are little better than displays of bias and prejudice.

Under the cover of a deceptive exterior everybody makes inferences like these: "What I have experienced is always valid and typical; I have done thus and so; therefore the world ought to approve what I do." Again, "The world owes me all I can get out of it; therefore it is justifiable for me to take all the profits I carn get." Or, "My family must have as much as anybody else's; hence this supposedly shady business deal must be acceptable." Or "I want this money (honor, rank, position, bodily gratification, source of power); what I want I ought to be allowed to get; therefore I am justified in getting this." Or we might cite examples of rank fallacies that pass muster in the subjective inner crypt.

Now when it comes to using this device in words for use upon other people, we find ourselves confronted with a problem in the choice and use of propositions. Every listener has his stock of pet notions, favorite truths, coddled fallacies, personal experiences, subjective judgments and conclusions. Mention these to him, and his mind, on the inside down deep, goes through quick chains of reasoning that bring a quick conclusion, hasty and undiscrimirative, biased, personal-emotional. What is commonly called the appeal to the emotions is just this use of propositions that touch off quick, habitual, undifferentiated chains of reasoning. And every mark that an emotion has is by them possessed: suddenness, lack of discrimination, general bodily set, and a response hidden for the most part from observation of others. Sometimes such trains of thought and inner reasoning are set off merely by the use of words; in fact such thinking is the result of wide connotation in use of words; that is what wide connotation meansthe starting to life of old paths of habitual thinking, the securing of definite reactions merely by the use of a word, the enforcing of conclusions, opinions, and convictions by suggestion.

To induce belief and acceptance on this level, use propositions that repeat vivid experiences of the people you are dealing with, make statements which, by likeness to common experience, have all the marks of plausibility, revive cherished memories and associations, say over pet beliefs-it matters not whether fallacious or sound-repeat old saws, proverbs, stock credos, dogmas, tribal incantations, liturgies, rituals, and any kind of familiar abracadabra. Especially significant are statements that are superfi- 
cially and instantly plausible, that look at first sight as if they could be nothing else than true and which are taken as valid without criticism; statements that leave the hearer in the attitude of saying, "That is the truth as far as I know, for all I could deny it; it surely sounds like truth; it can be true for all I dare deny." A very, very large part of verbal communication is of this type; in fact, it is the ultimate foundation of all possible thinking; it is useful at all times, and on some occasions it is the only sure way of winning a sufficiency of acceptance. Subjective Experience is a term that sums it all up; for brevity's sake it shall be referred to hereinafter as Experience.

(B) Belief Made on the Semi-Open Level. The type of reasoning next higher in social exposure is performed partly out of sight and partly in the open. On this level reasoning is more critical, more governed by the fear of discovery. Court testimony is the arch example; the jurors are supposed to get their judgment from what other men say, not from what they themselves have experienced directly. Yet any inference to the effect that such and such a witness is worth believing is often a hidden, subconscious affair. In court practice and in set debates the attempt is made to push inferences as to competency of witnesses into the open, and partly with success. But in the common walks of life such is not the case. In matters of religion, social caste, politics, partisanship of any kind; school loyalty, family allegiance-all our attitudes concerning these-or almost all-are made by much the same process and in the same place as purely subjective experience. Most of our authority, our acceptance of the experience of others in lieu of a like one of our own, we take without criticism and as undiscriminatingly as we take our personal experiences.

Inferences of this type would read, if once verbalized out in full, as follows: "Whatever the Bible says is true; this is in the Bible; therefore this must be true." Or, "Only honest and well-educated men act and look as this man acts and looks; therefore what he says must be true." Again, "What this writer, or speaker, has said about politics I have found to be true; therefore what he says about religion can also be accepted safely." Every time we accept an authority, we go through just such a sub-conscious reasoning process. It is often not free from fallacy. But such inferences can also be made clearly in the open; that is, a part of the inferring 
process is open. When a man confesses that he believes because the Bible says so, or because of the dicta of party leaders, social idols, teachers, parents, scholars, investigators, he makes part of his inference in the open, where it is exposed to inspection and criticism. But almost always in use of authority a part of his reasoming is done out of sight and is based on premises that he is not willing to divulge, or it follows logical methods that will not stand scrutiny; it is no stronger than illogical subjective Experience. Any statement that gets its validity by authority is of this semi-open, semi-hidden type of belief-making.

When we are considering a problem in speaking and writing, however, there is one type of authority that needs special consideration, one expert who is especially important-and that is the spealker or writer himself. A very large part-in fact a part surprisingly large - is accepted simply because he himself says it; it has no other claim to acceptance than that it is his say-so. There is no one name that satisfactorily denotes this type of acceptance; for lack of a better name it is called here by one of its aspects, Personal Prestige, or just plain Prestige. It includes all the belief-making instituted by a speaker's unsupported ipse dixi, unsupported except for the possession of a reputation as a great man, or an honest one, or for frankness, generosity, amiability, dominating vigor, fair play, personal charm, style of dress, wit, sentimentality, piety, aesthetic and artistic graces, and the air of being correct and in the right according to the tastes of the audience. Especial convincingness carries with his words if he is on our side, of our party, our church, lodge, clique; if he starts with a good showing of our pet notions, and interlards his speech with our favorite prejudices. When we listen to such a one, we know we are in the presence of a man with whom we are mentally and spiritually akin, and from that fact we know further that his judgments and conclusions are true and righteous altogether. This influence we acknowledge in the open by our acts, votes, and utterances; yet our cementing rationalisation is done under the rose, and we don't like to have it subjected to criticism.

Thus authority has the two important aspects, Testimony and Prestige; a kind of reasoning with some of the "therefores" and "becauses" in plain sight, but others snugly hidden from view. 
(C) Belief Made in the Open. Lastly there is that beliefmaking which is done in such a way that every step can be inspected and challenged. This is the kind made familiar by all texts on elements of logic and on argumentation. Despite its great importance to verbal discourse, little need be said about it here; it is too well known and too highly approved to need any amplified exploitation in this statement of theory. Suffice it to note that when one reasons in this wise, one makes all the joints obvious and clear. All the joining together is done under scrutiny where criticism can inspect every move. Induction piles up instances clearly and then clearly states the conclusion with a "hence" or a "therefore"; deduction' is equally meticulous about being perfectly visible and explicit; definition is accurate; classification is worked out with exactness and precision; abstraction observes religiously its essentials and non-essentials; generalisation shows unmistakably the relations between universals and particulars. This type of belief-making, when done carefully, submits itself to accurate briefing; in exceptional cases, where rational coherence is most rigorously enforced, a discourse can in reality be a spoken brief; that is to say, in cases where openness of process is most scrupulously desired, a well-devised brief can actually be the discourse itself. In this kind of fact-validation great importance attaches to relevancy, consecutiveness, and coherence. The links in the thought must be inescapable; when properly used, these links make the logical connections strong and obvious; when used wrongly they fail in the eyes of those who insist on seeing the joints made in the open. This method is properly called Reasoning.

Thus there are these three methods of making a proposition accepted as fact, or truth; Experience, Authority, Reasoning. Applying these now to the development of topics, we shall find that to develop any given topic in its place in the outline, profit can be had by applying all three kinds, but with varying emphasis. It is this variation in emphasis in the use of Experience, Authority and $O$ pen Reasoning THAT FURNISHES THE NECESSARY THREE METHods OF DEVELOPING THE TOPIC. The differences, as has been said, are determined by the three attitudes a hearer can take toward a topic proposition - acceptance, hesitancy, and opposition. Each of these attitudes reveals special needs and requirements that must be satisfied. Consideration of these needs and re- 
quirements will now yield a formal statement of the three methods of paragraph development. When we have found it, we shall have discovered the most significant way of providing a genuine woof and warp for the "intellectual" and the "emotional," for "reasoning" and "prejudice," for "rational belief" and "non-rational."

The Theree Methods of Paragraph Development

STEP 14-Develop the topic according to the method called for by the attitude of the audience.

Method 1; The Impressive. When the hearer already accepts the speaker's topic, what do the premises imply? First, that the best thing to do with the topic, if it is really at all worth using and amplifying, is to make it more acceptable still, to refurbish it, to make it shine anew, or better, to make it burn with a new heat. The surest way to do this is to revive the old experiences that have brought it favor as a conclusion or belief, to recite old happenings, description of old friends and places, cherished facts, creeds, prejudices; any of these, or all, will help make the topic bright and shining, will create for it a renewed interest, will give it a dominating power of attracting attention-as you will. Experience, thus, in the face of such a topic, is the sine qua non.

But Authority also can be used very effectively under such a circumstance; especially the citing of authority accepted in a poorly reasoned way. Also personal Prestige can do much to refurbish an old topic that has lost a little luster. Thirdly, an honest speaker or writer will do his best to use only sound open logic; fair definitions and classifications, decent inductions and deductions, respectable generalisations and analogies. Hence Reasoning also is a factor in this method. Yet it is only honest to say that sound Reasoning, though helpful, is not obligatory, as man is now constituted. It is not always necessary to be plainly logical, more's the pity. Many speeches made up wholly of accepted topics win high approval and get great results though thoroughly without visible and defensible logic; in fact this is the precise method used for ex parte pleas, appeals to partisanship, prejudice, bias, and selfish interest, and attempts merely to tickle the ears of the groundlings. Everybody knows that for these purposes not always is strict logic displayed.

Such a method is plainly one of impressing a topic on people who already accept it; it shall be called here, then, the Impressive 
Method. The way to describe it briefly, is to say that it must not omit reliance upon Experience, that it can draw much from Authority, and that, while strict Reasoning need not be revealed, honesty and a regard for one's reputation demand an adequate showing of sound logical processes.

This is the style that prevails throughout creed-defending sermons, platform-upholding stump speeches, commemorative addresses, occasional addresses of all kinds where the audience already is sure that it is in accord with the speaker and his message and is certain to agree with everything he says. It predominates in speeches of felicitation, congratulation, honor, and praise. It gives free play to imagination and fancy; the relaxing of the need for revealed logic gives them, not liberty only, but license. It turns readily to narration and description for its stuff, and it moves about in an air of near and dear things; of birds, flowers, trees, babies, mother, home, and heaven; of death-beds and of graveyards. Used vilely, it gives us clap-trap and sophistry; used honestly, it gives us much of our most compelling and gratifying literature.

The Impressive Method, then, is a way of choosing and organizing facts into pargraphs so that the effectiveness of the topic depends first upon the intimate use of Experience, secondly, upon successful rallying of Authority, and, thirdly, upon the adequate use of careful logic, Reasoning. When presenting a topic to an audience that already accepts it, the problem of how to do it best will be met by asking first if Experience has been given its full place, then by inspecting the possibilities for calling in Authority, and finally by testing the Logic to see if it is good enough. No absolute test is involved; all is relative, a matter of emphasis, of looking at certain processes first for the surest solution and others later for what help they can render.

Method 2; The Didactic. What are the necessities when the audience is neither for nor against the topic? The situation may arise from more than one cause; ignorance, indifference, halting between two opinions, balancing deliberately two lines of thinking, research, or theory. The ignorant need informing, the indifferent need enlightening, the doubtful need convincing, and the deliberate need settling. In any and all of these cases one necessity is paramount; the listener must be treated as a rational being; he must be shown a logical connection between the topic 
The is asked to accept and the propositions that support it. The extermals of the reasoning process must be in sight or else his needs are not met. Doubt, ignorance, hesitancy, weighing of issues cannot be turned to acceptance without a clear display of fair reasoning. Therefore in the presence of such an attitude the one thing the speaker must do is to use open, frankly-displayed marks of logic; classification must be comprehensive, definition must mark off with precision, induction must move toward a logically sound conclusion, deduction must follow the laws of the syllogism, and generalisation must be full and convincing. The one best way to do this is to inform the ignorant, settle the doubter, and satisfy the seeker. Hence the most important of all ways of fixing a conclusion is $\mathbb{R e a s o n i n g , ~ t h e ~ w a y ~ t h a t ~ c a n n o t ~ b e ~ i g n o r e d , ~ t h e ~}$ type that goes farthest in solving the problems of the situation.

But there is another effective way of banishing doubt: Authority. The courts use it altogether; with them nothing else counts. And for a very powerful reason: any issue that is stiff and unyielding must inevitably refer to authorities; in the last analysis, when two contending ideas clash, the only possible ultimate arbiter is a third person accepted as competent to pronounce the truth. Court procedure makes it easy to confound expert testimony with reasoning itself, this being the only kind of evidence there allowed-for the very best court reasons. Personal impressions are discredited, guesses are ruled out, bias is in every way submitted to the test of competence in reporting as expert authority. But in every-day life we do not so order it; we accept hearsay, we swallow the sayings of biased people, quite contrary to court custom we are more likely to accept authority than to question it. In particular we accept doubted propositions. because we like the man who utters them, submitting thus to his Prestige. In hearing speeches and reading printed matter we do this to an amazing extent; we solve many a problem merely by accepting what a man says because we like bis style-literary, sartorial, elocutionary, social. So, second in importance in solving problems is Authority.

Thirdly, no problem could be satisfactorily met logically without a basis of elementary fact, without premises that are already accepted. These must be found in the audience's past experiences, past prejudices, opinions, beliefs, habitual thinkings. To support premises, other facts are needed, other experiences experienced, 
almost as much so as citation of experts and the power of Prestige. People differing so, it is hard to find enough supply of a genuinely common fund, so in general Authority is slightly more reliable than Experience in the problem-solving method, the Didactic.

This is the type of topic development sometimes called pure argument. As a matter of note there is no such thing; what we commonly call argument is only exposition with a therefore attached. Every exposition contains an implied therefore; argument merely attaches it and says it out plainly. Exposition has as much need of open logic as argument. Excellence in exposition is gauged by the strictness of the reasoning used. It is the way of composing that is needed for treatises, text books, monographs, theses, informative essays, reports, academic lectures, the didactic sermon, and all kinds of explanation. As has been said, it can be no more than a brief adapted to running discourse, with its 1,2 , and 3 , and its $a, b$, and $c$. In the application of it the one inescapable source of belief is Reasoning; then Authority, properly accredited, gives Reasoning its best defence, and, thirdly, Experience plays its part by furnishing the ground work of all Reasoning.

This method comes well under the name Didactic; primarily it aims to instruct.

Method 3; The Conciliatory Method. Next, what must be done by way of selecting facts and arranging them when the audience is opposed? There is one easy answer; the speaker is immediately put to all his trumps; in the face of opposition that is earnest and clear-eyed, any speaker will need to use everything he has in the way of belief-making devices. At that, cases will arise when there are not enough facts in his little world to turn the trick. But assuming now that he deals with possible cases, what is the belief-making method that is most certain to smooth down opposition? We all know that much of the time in such cases the sure thing not to do is to argue; "argument" only makes the opposition stiffer. Hence Reasoning is not surely effective. We know also that what makes the opposition is a difference in experiences, in accepted opinions. Experience too is not certain to win. Does the same hold for Authority? Not so greatly; in Authority we find the best hope for allaying hostility to a topic. This is like enough to the way civilized men commonly settle disputes; they refer them to an arbiter, a referee. So must the speaker. He gets 
hold of a hostile audience best by referring the case for adjudication to a third party. To quote testimony is to bring the case to arbitrament, and men know that if they cannot agree, they must submit most matters to adjudication. When opposition is aggressive and unyielding, this is the only way to keep up diplomatic conversations; otherwise communication is off, and there is no speaking or writing. Hence it argues that the best way of developing a topic when the audience thinks it false, is to cite accepted Authority.

But speaking and writing offer one peculiar opportunity for reference to Authority, and that is in making the speaker or writer himself authoritative enough to validate what he says. Hence Prestige plays a large part in wearing down hostility; the audience can be disarmed by the speaker's own personality and by his own manner of speaking. A showing of honesty-not necessarily a parading of it-of fairness, of generosity, of sympathy, and many other personal graces can be used to disarm hostility. Propositions revealing these graces get acceptance at the start and then give carrying power to others that follow. They need have no logical relation to the speech that follows, except the most remote and strained, and still they are an organic part of the speech and of its results. The statement that the speaker is glad to be present can carry conviction by the look on his face; this proposition in turn may get lodgment for the next that it is well that they are to discuss the issue before them; and then this can prepare the way for saying that whatever this audience does will surely be well-considered, etc., etc. Not of necessity at all shall such propositions be insincere, be merely the tricks of a charlatan, nor the stock phrases of an unthinking parrot. They can come from the innermost heart, and when genuine are an important and organic part of the speech or writing. So Prestige is of prime importance, as well as Testimony, in melting the ice of opposition or, to reverse the figure, in quenching the fires of hostillity. In any case Authority is the prime helper in the method needed when the topic is rejected.

Another way of describing this method is to say that, in common with any possible method that works, it must use only facts, only propositions that the audience accepts. It must begin only with the known-better, the accepted. Then it must lead from one accepted statement to another in such a way that the audience 
will consent to follow. When opposition is strong, then the very surest way is either by talking about the audience and the speaker and the occasion, or else by citing a competent, impartial third party - the use of Authority. It is the safest and surest way of going from the known to the unknown. Once the speaker has found a safe basis and has had attention for even a short time, his audience accredits him with soundness of judgment, knowledge of facts, and fairness, and so opens the way for Prestige to get in its work. Later he can make headway without reading from a book or a paper or talking about the obvious things present in the room and the community. And on the Prestige thus gained he can rely rather strongly, at least until he unfortunately makes a tactless error by bringing in something the audience refuses to accept. Then he has to begin all over again.

With an opening made by Authority of one kind or another, what is the next necessity? Obviously, careful and overt Reasoning. Authority can open diplomatic communications; it cannot settle disputes; it can bring the issue into a fair court; and once there the issue must be reasoned to a fair conclusion. No need to emphasize this need; it is inescapable. Second in importance-no, not so much in importance as in time-in the face of opposition is open Reasoning, clear and honest logic. No opponent is likely to be won over unless a "clear case" can be made according to the accepted rules of logic and rhetoric.

Finally in order to reason fairly or to use obvious things for the establishment of Prestige, use must be made of Experience, the speaker must talk of things the audience knows about; otherwise he cannot reason to any valid effect; he goes over their heads. The propositions he picks as links in his logical train and as bases for Prestige must to the audience be true, accepted as facts. Hence by no means can the subjective Experience of the audience be slighted. It is called third in this method simply because there can be no start without some kind of Authority and no progress without Reasoning. It would be as fair to say that there could be no conclusion without Experience. The simple fact is that to describe this method accurately we must say that in it the speaker must use every source of belief to its fullest capacity, especially when the opposition is wide awake and intense.

This method lacks a satisfying name; the one seeming best is Conciliatory, suggesting the reduction of opposition to hesitancy 
and then to acceptance, and finally to acceptance that is sufficiently strong.

These three methods of developing a topic are presented as the sole valid way of meeting that requirement for differentiating between the "intellectual" and the "emotional." As far as there is definite meaning to the term "appeal to the intellect," it is provided for by the Didactic Method; what is meant by the "emotional" is met by the Impressive Method; while that something called a "persuasive style" intended to meet hostility, is provided for by the Conciliatory Method. These methods are offered as a way of providing a genuine woof and warp; they accomplish this by recognizing and properly emphasizing the different ways of fixing beliefs; three in number, instead of the two of tradition. These methods when properly applied to the development of topics-the first outbreak of the process into coherent discourse - gather up all the momentum gained by the preliminary Analysis-proper choice of action, insistence upon a specific Demand, deciding upon the Main Proposition, the study of the hearer's personal and social nature, the making of a Brief, and the framing of an Outline-gather their aggregated power and hurl it at the selected vulnerable spot in the action system of the audience. Thus the method brings to bear both the subjective and the objective pressure, from the very start of the process right on down to the moment of choosing propositions for actual presentation. It is thus consistently objective, holds to a flexible standard, and furnishes a unified process throughout.

This step in the process is clearly worthy of a book by itself; the three methods are, because of the needs of compression, here merely sketched. In fact, a whole system of composition can be written around them, one that will go beyond methods now under suspicion because not true to the facts. It will be at all times openly and boldly objective, will be based on verifiable actualities, and so can be made of value in actual practice.

It will be noted that this method does not commend "thumb rules." That there is no royal road to success in speaking or writing is a platitude; no method can make speech composition really easy; the best it can do is to make it easier to keep on the track of one's intentions and to come out at the hole intended. What this system provides best is a means of avoiding mistakes, of reducing wandering, of shooting straight, of finding the joints 
that need inspection and lubricating, of cutting out waste and false motion. It will not do a student's thinking for him; only his own knowledge and sagacity can save him if he is saved; for a. method which, like this, operates by a flexible standard, can be of service only in the hands of people who are first well informed and then rich in good sense.

In the study of these three methods lies also a sound basis for literary criticism; it is the one safe way of differentiating sound composition from sophistry. Any critical theory based upon notions of absolute standards is built on shifting sands. Sophistry can be most satisfactorily defined in terms of these methods; it is that type of composition which uses the wrong method for a given occasion. To use the Didactic or the Conciliatory method on an audience already convinced is simply to bore them and to waste time; yet that is not ethically reprehensible. But to face an audience that seeks light or, much worse, to assume the pose of one who is to shed light, and then feed people nothing but subjectified opinions or pass out merely old warmedover dishes, to play upon their gullibility or their faith in you while you give only that which is superficially plausible and tickles their prejudices, without holding to a strict logical method to fulfill your promises as teacher and guide-this is the essence of sophistry. This is the method of the political charlatan, of the shyster lawyer, of any rank partisan, of the opinionated egotist, of the one who speaks as if from Olympus. It is affected by certain evangelists, by party politicians, by crooked lawyers, and by a certain patrician type of literary critic. Sophistry is giving to the audience before you stones when their call is clearly for bread. Its worst manifestation is the carrying of a point without dealing with careful discriminations. It arises from mental blind spots and plays on those of the audience. And it is not inherent in any system of rhetoric; it is in the heart always of the sophist. There is not really sophistry; there are just sophists, some ignorant, some crooked, and others hyper-opinionated.

Wording the Proposition

STEP 15-Use words so as to give to propositions their highest acceptance value.

The last step in the Process of Persuasion, of gaining acceptance to the Main Proposition that is equivalent to the action desired, is selecting and arranging the words out of which propo- 
sitions are made. Here again comes the intermingling of open and hidden, the "rational" and the "emotional." Every word used is a factor in the open reasoning employed, the logic of the sentence of which it forms a part. Grammar is but one form of applied logic. Grammar, syntax, and rhetoric work partly as a matter of palpable logic and partly as a matter of the inner workings of subjective bias and prejudice-Experience.

Here the objective attitude is obligatory still. A sentence is more or less futile in getting a desired result unless it be so framed that every word fits into the peculiar nature of the hearer. Also the order and proportion in which they are used must conform to existing experiences of the hearers. Accuracy of denotation, wideness and richness of connotation, propriety, good use, all play an important part in making the proposition acceptable. It is obvious enough that the best of plans can be spoiled by carelessness or ignorance in the use of words, just as a poor plan or an arrant falsehood can be made of some effect by cleverness or adroitness. A "solid" case fully as much as a "weak" one cannot dispense with knowledge and sagacity in the choice and use of words.

But this has all been set out in the science of rhetoric. Every device of rhetoric, every accepted rule for the choosing and ordering of words, every use of figures of speech, idiom, the standard tricks of phraseology, can be shown to be the method of selecting and arranging words to get the maximum of acceptance to a proposition. And the approved rules of rhetoric are so many approved ways of applying both "hidden" and "open" logic to the use of words for making propositions acceptable to hearers and readers.

\section{Implications of a Purely Objective Method}

This method meets the following long-accepted requirements of "argumentation" and public address:

It emphasizes the necessity for being logical; and all the time; in this system reasoning operates at every stage of the process.

It finds a systematized place for the "emotions."

It shows the relation of truth to action, how truth plays its part in the action-producing process.

The brief is shown to be just what it has long been considered, indispensable to sound discourse. 
The psychology of the individual is given a consistent relation to the psychology of the crowd and the audience.

Prejudices, biases, personal idiosyncrasies are shown to be an organic part of all discourse.

The function of the "ends" of speaking are shown in a thoroughly comprehensive way, in that each speech must have an end of its own that is more important than any "general" end.

The objective attitude is held rigidly throughout.

The three factors in discourse, speaker, hearer, and facts, are one of the foundations of the method.

The system gives a demonstration of how a resolution, or main proposition, is derived, how the psychology of the speaker is linked by logical processes to the psychology of the hearer; how the analysis moves by constant consideration of the relation of the psychological with the logical.

It provides an exposition of the place and function of each of the "forms of discourse"; occasional, dedicatory, forensic, deliberative, etc. Obviously in practice they overlap, and the explanation is found in the flexibility of the outline, which is always developed from the specific nature of the occasion, rendering such divisions helpful, but not definitive.

Knowledge and Sagacity, J. S. Mills' most proper gauges and weather-cocks of logical efficiency, play a strictly first part in the process, furnishing the escape from a standard of absoluteness, and supporting the standard of sufficiency.

It provides rules, but not "thumb rules"; steps that are in effect the statement of principles of guidance in creative thinking.

It enforces the pedagogical principle that the best teaching method is that which leads to self-analysis and self-criticism, making the student a competent critic of his own efforts, and showing him at what points he can apply criticism with the greatest profit.

It shows that composition is method; method in making plans and outlines, and method in the developing of discourse from topics.

It is so conceived that the fixed and thoroughly established principles of rhetoric not only fit in, but find necessary for adequate explanation, the background of facts insisted upon by this method.

It removes the ambiguities involved in the concept of presuasion as (1) the appeal to the emotions as against the intellect, 
(2) as the attempt to overcome the prejudices and biases of the audience, and (3) the kind of composition that is most intimate, concrete, and a part of the sentimental experience of audiences.

It fits in throughout with the doctrine that the way to win men is to hold their attention on favorable terms; the whole method could be stated in every detail in this terminology. The principle is most sound, needing now only a formal and systematic expllication of its intricate and inter-locking workings. Translate the term "action" here into "attention," and the two systems are at one in their conclusions. 